W.S. Beattie MD PhD FRCPC, D.N. Buckley MD FRCPC, J.B. Forrest MB PhD FRCPC

\title{
Continuous infusions of atracurium and vecuronium, compared with intermittent boluses of pancuronium: dose requirements and reversal
}

This study was designed to determine the effect of prolonged infusion on the ease of reversal of atracurium and vecuronium, and whether factors which potentiate the block delayed reversal. In phase one, 40 patients were randomized (double blind) to determine the steady state conditions for atracurium and vecuronium. Fourteen atracurium patients and 17 vecuronium patients were evaluable. The unblinded second phase involved the steady state conditions using halothane or isoflurane and atracurium infusions. The infusion required for $95 \%$ twitch depression $\left(T D_{95}\right)$ for atracurium was $7.6 \pm 1.1 \mu \mathrm{g} \cdot \mathrm{kg}^{-1} \cdot \mathrm{min}^{-1}$. The requirement for vecuronium changes with time: $T D_{95}$ at 30 min was $1.01 \pm 0.16$, at $60 \mathrm{~min} 0.89 \pm 0.12$ and after $90 \mathrm{~min}$ $0.85 \pm 0.17 \mu \mathrm{g} \cdot \mathrm{kg}^{-1} \cdot \min ^{-1}(P<0.05)$. The mean $T D_{95}$ was 0.94 $\pm 0.23 \mu \mathrm{g} \cdot \mathrm{kg}^{-1} \cdot \mathrm{min}^{-1}$. Multivariate regression analysis of the infusion data revealed a vecuronium model predicting $T D_{95}$ by the duration of infusion $(P<0.05)$ and weight $(P=0.05)$. Atracurium $T D_{95}$ was predicted by age $(P=0.05)$. The addition of an inhalation agent to atracurium reduced the infusion rate by $2.01 \pm 0.28 \mu \mathrm{g} \cdot \mathrm{kg}^{-1} \cdot \mathrm{min}^{-1}(P=0.0001)$ for each increase in $M A C$. The mean reversal times for atracurium with three different anaesthetics and for vecuronium were not different. Reversal of pancuronium blockade, from less profound twitch depression (86.4 vs $95 \%$ ) took twice as long as for atracurium and vecuronium for which the following predictors were identified: age, weight, duration of infusion, level of blockade, and type of

\section{Key words}

ANTAGONISTS, NEUROMUSCULAR RELAXANTS: atracurium, vecuronium, pancuronium.

From the Department of Anaesthesia, McMaster University, 1200 Main St. W., Hamilton, Ontario L8N 3Z5.

Address correspondence to: Dr. W.S. Beattie.

Acceped for publication 9th July, 1992. anaesthetic, using a stepwise regression model. Forvecuronium. age (coeff $2.84 \pm 0.51 P=0.0001$ ) and duration of infusion (coeff $0.12 \pm 0.02 P=0.0002$ ) were significant predictors. Age was the only predictor of the time to reverse block after atracurium blockade with all types of anaesthetic $(P=0.05)$.

Cette étude a pour but de déterminer l'effet et la réversibilité d'une perfusion prolongée d'atracurium ou de vécuronium, ainsi que les facteurs qui peuvent retarder la décurarisation. Dans la première étape de l'étude, 40 patients ont été désignés aléatoirement (méthode à double insu) pour déterminer les conditions d'équilibre de l'atracurium et du vécuronium. Quatorze patients furent conservés pour l'atracurium et 17 pour le vécuronium. La deuxième étape, à découvert, a étudié les conditions d'équilibre obtenues avec l'halothane oul'isoflurane et des perfusions d'atracurium. La perfusion requise pour une dépression du twitch de $95 \%\left(T D_{95}\right)$ est de 7,6 $\pm 1,1$ $\mu \mathrm{g} \cdot \mathrm{kg}^{-1} \mathrm{~min}^{-1}$ avec l'atracurium. Les besoins de vécuronium varient avec le temps: le $T D_{95}$ à 30 minutes, de 1,01 $\pm 0,16$; à 60 minutes de $0,89 \pm 0,12$ et après 90 minutes, de 0,85 \pm $0,17 \mu \mathrm{g} \cdot \mathrm{kg}^{-1} \cdot \min ^{-1}(P<0,05)$. La valeur moyenne de $T D_{95}$ est de 0,94 $\pm 0,23 \mu \mathrm{g} \cdot \mathrm{kg}^{-1} \cdot \mathrm{min}^{-1}$. L'analyse par régression multivariée des doses de perfusion de vécuronium donnent une prédiction de la $T D_{95}$ dépendant de la durée de la perfusion $(P$ $<0,05)$ et du poids $(P=0,05)$. La TD 9 de l'atracurium dépend de l'âge $(P=0,05)$. L'adjonction d'un agent d'inhalation à l'atracurium réduit la dose perfusée à 2,01 $\pm 0,28$ $\mu g \cdot \mathrm{kg}^{-1} \cdot \mathrm{min}^{-1}(P=0,0001)$ pour chaque augmentation $d u$ $M A C$. La durée moyenne de décurarisation pour l'atracurium avec trois agents anesthésiques différents et pour le vécuronium n'est pas différente. La réversibilité d'un bloc au pancuronium à partir d'une dépression du twitch moins profonde (86,4 vs 96\%) est deux fois plus longue que celle de l'atracurium et du vécuronium. Les facteurs suivants doivent être considérés: l'âge, le poids, la durée de la perfusion, le degré du bloc et l'agent anesthésique étudiés avec un modèle de régres- 
sion en palliers. Pour le vécuronium, l'âge (coeff. 2,84 $\pm 0,51$, $P=0,0001$ ) et la durée de perfusion (coeff. $0,12 \pm 0,2, P=$ $0,0002)$ sont des prédicteurs significatifs. L'age est le seul prédicteur de la durée de décurarisation après un bloc à l'atracurium avec tous les types d'agents anesthésiques $(P=$ $0,05)$.

The introduction of muscle relaxants into clinical anaesthesia occurred concomitantly with an increase in anaesthetic complications.' Nineteen percent of anaesthetic deaths have been attributed to respiratory failure ${ }^{2}$ from residual muscle relaxants. Complete return of muscular activity to preoperative levels is difficult to determine clinically. ${ }^{3}$ Patients can sustain ventilation with normal carbon dioxide levels but may not be able to maintain airway patency. ${ }^{4.5}$

Two separate studies have shown that as many as $42 \%$ of patients may return to the recovery room with inadequate reversal of muscle relaxation. ${ }^{6.7}$ The use of atracurium and vecuronium reduces the incidence of incomplete reversal. ${ }^{8.9}$ With longer procedures the intermediate acting muscle relaxants require frequent boluses or a steady state infusion. Reversal of atracurium and vecuronium after steady state infusion has been previously studied. $^{10}$ Using a balanced anaesthetic technique, neuromuscular function after both atracurium and vecuronium returmed to $85 \%$ of control within $20 \mathrm{~min}$. However, problems were encountered in reversing the block in elderly patients. Inhalational agents have been found to

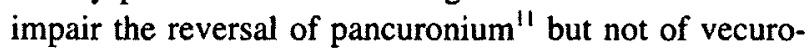
nium. ${ }^{12}$ While the inhalational agents are known to potentiate atracurium ${ }^{12,13}$ the effect has not been systematically studied with steady state infusions. The effect of inhalational agents on reversal after steady state infusion of atracurium has not been studied.

The present study was undertaken to define the factors which predict the timing of clinically acceptable reversal of muscle relaxants after steady state infusion. This was compared with the reversal of pancuronium given by intermittent boluses, as this is a frequent mode of muscle relaxation in longer lasting cases. We studied the doses of atracurium and vecuronium required for surgical relaxation (95\% twitch depression) when given by steady state infusion, determined the potentiation of neuromuscular blockade with atracurium by isoflurane and halothane, and compared these with intermittent injections of pancuronium. Reversal of the blocks was then assessed and compared.

\section{Methods}

This study was approved by our institutional review board. American Society of Anesthesiology class I or II patients scheduled for elective surgical procedures were eligible for study. Patients in whom average hourly blood loss was anticipated to exceed $200 \mathrm{ml} \cdot \mathrm{hr}^{-1}$ were excluded, as were patients receiving drugs which are known to potentiate or antagonize neuromuscular blockade.

\section{Anaesthetic}

Patients received no premedication. An intravenous infusion of normal saline was established in the operating room. Diazepam $0.2 \mathrm{mg} \cdot \mathrm{kg}^{-1}$ plus fentanyl $\left(10 \mu \mathrm{g} \cdot \mathrm{kg}^{-1}\right)$ or sufentanil $\left(1 \mu \mathrm{g} \cdot \mathrm{kg}^{-1}\right)$ was administered prior to induction of anaesthesia with thiopentone (up to 4 $\mathrm{mg} \cdot \mathrm{kg}^{-1}$ ) which was then maintained with oxygen $(30 \%)$ and nitrous oxide $(70 \%)$. The trachea was intubated without the aid of muscle relaxation. End-tidal carbon dioxide $\left(\mathrm{PETCO}_{2}\right)$ was measured with an on-line mass spectrometer (Sara System P.P.G. Industries, Lexana, Kansas) and maintained by adjusting minute ventilation between 36 and $44 \mathrm{mmHg}$. Patients in whom the $\mathrm{PETCO}_{2}$ decreased outside these variables were excluded from analysis (one patient randomized to receive atracurium could not achieve a $\mathrm{PETCO}_{2}$ above $31 \mathrm{mmHg}$ despite repeated attempts at reducing ventilation and flow rates). Oesophageal or rectal temperature was monitored in all patients, and temperature was controlled with warming/cooling blankets, warmed intravenous fluids, and humidified gases. One patient was excluded from analysis due to hypothermia. Blood loss was recorded on an hourly basis. Seven patients (four atracurium and three vecuronium) were excluded after being randomized due to excessive blood loss (greater than $200 \mathrm{ml} \cdot \mathrm{hr}^{-1}$ ).

\section{Measurement of the effect of muscle relaxants}

Using the Datex 221 NMT (Datex Instrumentarium Corp. Helsinki, Finland), a commercially available neuromuscular monitor, the EMG signal from the hypothenar eminence was monitored. A custom-designed hand splint, with foam backing, immobilized the hand. The hypothenar muscles are almost solely innervated by the ulnar nerve, have little motion when stimulated, and their activity correlates with respiratory functions. ${ }^{4}$ The arm was wrapped with a heated blanket to reduce heat loss. Monitoring was commenced after tracheal intubation and continued for ten minutes. The instrument was recalibrated prior to the administration of muscle relaxants, a procedure which has been found to minimize the drift that has been described with the NMT.

Patients were then paralysed with the appropriate drug bolus (atracurium $0.5 \mathrm{mg} \cdot \mathrm{kg}^{-1}$ or vecuronium 0.1 $\left.\mathrm{mg} \cdot \mathrm{kg}^{-1}\right)$. At the return of a single twitch $\left(\mathrm{T}_{1} / \mathrm{T}_{\mathrm{lc}}=1 \%\right.$ ) the infusion was started. The initial infusion rate for atracurium was $8 \mu \mathrm{g} \cdot \mathrm{kg}^{-1} \cdot \mathrm{min}^{-1}$ and for vecuronium was $1 \mu \mathrm{g} \cdot \mathrm{kg}^{-1} \cdot \mathrm{min}^{-1}$. The level of blockade was assessed 
every $20 \mathrm{sec}$ using train-of-four stimulation. The infusionrate $\left(\mathrm{TD}_{95}\right)$ which maintained a block of $95 \%$ twitch depression $\left(T_{1} / T_{1 c}=5 \%\right)$ was determined. The level of block, the infusion rate, $\mathrm{PETCO}_{2}$, temperature, heart rate, and blood pressures were recorded every five minutes.

The time of reversal of neuromuscular blockade was defined as the time to achieve $\mathrm{a} \mathrm{T}_{4} / \mathrm{T}_{1}$ ratio of 0.8 . Previous studies ${ }^{4}$ have shown that an EMG $\mathrm{T}_{4} / \mathrm{T}_{1}$ ratio of 0.6 is associated with reduced hand grip and negative inspiratory pressure. Others have shown, in unanaesthetized subjects, reduced inspiratory pressure at a $\mathrm{T}_{4} / \mathrm{T}_{1}$ ratio of $0.6 .^{5} \mathrm{~A}$ train-of-four ratio of 0.7 is the level of fade accepted as adequate reversal ${ }^{15.16}$ when mechanical force/contraction measurements are used. Levels less than 0.7 have shown some instances of ventilatory impairment. ${ }^{15}$ Kopman $^{16}$ demonstrated that the mechanical train-of-four lags behind the EMG response using the Datex NMT 221. Therefore the EMG train-of-four ratio must be $>0.7$ to correspond with the 0.7 level of mechanical monitoring. We arbitrarily chose the level of 0.8 .

Groups A1 (atracurium and narcotic) and V (vecuronium with narcotic) were studied in a blinded manner so that decisions about changes in dose would be unbiased. Both drugs were prepared in equal volumes (based on an atracurium/vecuronium potency ratio of $1 / 8$ ). In determining this ratio we examined steady-state infusion data. ${ }^{17-22}$ The infusion rates for vecuronium ranged from 0.11 $\mu \mathrm{g} \cdot \mathrm{kg}^{-1} \cdot \mathrm{min}^{-1}$ to $2.67 \mu \mathrm{g} \cdot \mathrm{kg}^{-1} \cdot \mathrm{min}^{-1}$ to maintain $90 \%$ twitch depression; a 24-fold variation. Atracurium steadystate infusions ranged from 3.7 to $14.3 \mu \mathrm{g} \cdot \mathrm{kg}^{-1} \cdot \mathrm{min}^{-1}$, a 3.9-fold variation. Utilizing a latin square* we determined a potency ratio of 7.87:1 (approx 8:1). Since the comparisons were blinded the relative infusion rates reflect the true potency ratio in our population.

Five groups were studied after random allocation. Group A1 and V received a nitrous/narcotic anaesthetic and the muscle relaxant. Group A2 received a nitrousnarcotic anaesthetic and atracurium infusion, with isoflurane. In group A3 the inhalation agent was halothane. Group $P$ received a nitrous/narcotic anaesthetic and pancuronium $\left(0.1 \mathrm{mg} \cdot \mathrm{kg}^{-1}\right.$ to facilitate intubation $)$ and by intermittent bolus as appropriate to maintain $95 \%$ twitch depression. The concentration of inhalational agent was adjusted according to heart rate and blood pressure responses. The end-tidal concentrations of either isoflurane or halothane were recorded every five minutes. The infusion rate, level of block, and end-tidal agent were

*This method takes the mean value of the ratios obtained by dividing the high vecuronium level by the low atracurium level; the low vecuronium level by the high atracurium level; the low by the low and high by the high levels. unchanged for three consecutive measurements (15 min) before being analyzed.

\section{Reversal of muscle relaxation}

Neostigmine $50 \mu \mathrm{g} \cdot \mathrm{kg}^{-1}$ and glycopyrrolate $10 \mu \mathrm{g} \cdot \mathrm{kg}^{-1}$ were administered to antagonize neuromuscular blockade. Immediately after the neostigmine bolus the muscle relaxant infusion was stopped, and the inhalation agent was turned off. The rates of recovery of $T_{1} / T_{l c}$ and $T_{4} / T_{1}$ were noted at control, one minute, two minutes and five minutes after the neostigmine bolus and every three minutes thereafter. Neuromuscular blockade was monitored until $\mathrm{T}_{4} / \mathrm{T}_{1}$ was $>0.8$.

\section{Statistics}

The demographic and infusion data, recovery times, and effect of inhalational agents were analyzed using oneway analysis of variance. If significant differences were encountered Student's t tests with Bonferroni correction were performed. In addition, factors affecting infusion rates and neuromuscular reversal were analyzed using a forward stepwise multiple regression model. Variables had to increase the predictive value by $P=0.05$ before entering the model. In all statistics a $P$ value of 0.05 or better was considered significant.

\section{Results}

\section{Demographic data}

The age, weight and duration of infusions were similar in all four infusion groups (Table I). Although the duration appears to be shorter for the vecuronium group this difference did not achieve statistical significance.

\section{Neuromuscular doses}

The infusion rate of atracurium at the time of reversal was $7.6 \pm 1.1 \mu \mathrm{g} \cdot \mathrm{kg}^{-1} \cdot \mathrm{min}^{-1}$ in group A1. The mean dose of vecuronium at the time of reversal was $0.94 \pm 0.23$ $\mu \mathrm{g} \cdot \mathrm{kg}^{-1} \cdot \mathrm{min}^{-1}$. There appeared to be more variation in the vecuronium infusions. Using analysis of variance we compared the infusion rates in the two groups receiving nitrous narcotic anaesthesia (groups $A 1$ and $V$ ) at 30,60, and $90 \mathrm{~min}$ of infusion (Table II). Vecuronium infusion rates decreased with time $\left(1.01 \pm 0.16 \mu \mathrm{g} \cdot \mathrm{kg}^{-1} \cdot \mathrm{min}^{-1}\right.$. $0.89 \pm 0.12 ;$ and $0.85 \pm 0.17 \mu \mathrm{g} \cdot \mathrm{kg}^{-1} \cdot \mathrm{min}^{-1}$ respectively $P=0.01)$. We found no such decline with atracurium Age, weight, duration of infusion and inhalation agents were entered into a forward stepwise multivariate regression to model predictors of dose. The results of this analysis are seen in Table III. Atracurium and vecuronium have different models for predicting dose. The significant predictors for atracurium include age (coeff $=0.28 \pm 0.01$ $P=0.03)$ and inhalational agent (coeff $=-2.02 \pm 0.29$ 
TABLE I Demographic mean \pm SD

\begin{tabular}{lllll}
\hline Study group & $\begin{array}{l}\text { Number of } \\
\text { patients }\end{array}$ & Age $(y r)$ & Weight $(\mathrm{kg})$ & $\begin{array}{l}\text { Anaesthesia } \\
\text { time }(\text { min })\end{array}$ \\
\hline Atracurium/narc & 14 & $41.2 \pm 24.0$ & $65.0 \pm 16.0$ & $156.0 \pm 18.0$ \\
Atracurium/isofl & 14 & $37.3 \pm 19.0$ & $67.0 \pm 12.0$ & $163.0 \pm 19.0$ \\
Atracurium/halo & 14 & $43.0 \pm 9.0$ & $66.0 \pm 18.0$ & $148.0 \pm 22.0$ \\
Vecuronium/narc & 17 & $41.6 \pm 21.0$ & $63.0 \pm 17.0$ & $139.0 \pm 19.0$ \\
Pancuronium/narc & 16 & $44.1 \pm 18.0$ & $65.0 \pm 21.0$ & $147.0 \pm 14.0$ \\
\hline
\end{tabular}

TABLE II Effect of duration on the infusion requirements (Effect of infusion time on the $\mathrm{TD}_{95}$ : comparison of atracurium and vecuronium in patients receiving nitrous/narcotic anaesthesia (mean \pm SD))

\begin{tabular}{llllll}
\hline Agent & $30 \mathrm{~min}$ & $60 \mathrm{~min}$ & $90 \mathrm{~min}$ & $f$ & P value \\
\hline $\begin{array}{l}\mathrm{ATR} n=14^{*} \\
\mu \mathrm{g} \cdot \mathrm{kg}^{-1} \cdot \mathrm{ml}^{-1}\end{array}$ & $8.10 \pm 0.21$ & $7.90 \pm 0.18$ & $8.02 \pm 0.17$ & 0.5 & 0.2 \\
$\begin{array}{l}\mathrm{VEC} n=17^{*} \\
\mu \mathrm{g} \cdot \mathrm{kg}^{-1} \cdot \mathrm{ml}^{-1}\end{array}$ & $1.01 \pm 0.16$ & $0.89 \pm 0.12$ & $0.85 \pm 0.17$ & 3.82 & 0.03 \\
\hline
\end{tabular}

* Six patients were excluded from atracurium analysis due to protocol violations; four for blood loss in excess of $200 \mathrm{ml} \cdot \mathrm{hr}^{-1}$; one for hypothermia; and one for hypocarbia. Three patients were excluded from vecuronium analysis all for blood loss in excess of $200 \mathrm{ml} \cdot \mathrm{hr}^{-1}$.

TABLE III Multivariate predictors of steady state $\mathrm{TD}_{95}$ for atracurium and vecuronium

\begin{tabular}{llcl}
\hline & Variable & \multicolumn{1}{l}{ Coeff } & P value \\
\hline Atracurium & Age(yr) & $0.28 \pm 0.01$ & 0.03 \\
& Wt(kg) & $0.004 \pm 0.06$ & 0.509 \\
& MAC(age adjust) & $-2.02 \pm 0.29$ & 0.0002 \\
& Duration(min) & $0.007 \pm 0.11$ & 0.923 \\
& & & \\
Vecuronium & Age(yr) & $0.007 \pm 0.004$ & 0.068 \\
& Wt(kg) & $0.006 \pm 0.003$ & 0.05 \\
& Duration(min) & $0.005 \pm 0.002$ & 0.03 \\
& MAC* & & \\
\hline
\end{tabular}

*Patients receiving vecuronium did not have inhalational agents at any time.

Regression equations for stepwise models are: Atracurium $\mathrm{TD}_{95}$ $\left(\mu \mathrm{g} \cdot \mathrm{kg}^{-1} \cdot \mathrm{min}^{-1}\right)=8.36-2.02(\mathrm{MAC})-0.028$ (age) $\mathrm{f}=30.82$ $P=0.0002$. Vecuronium $\mathrm{TD}_{95}\left(\mu \mathrm{g} \cdot \mathrm{kg}^{-1} \cdot \mathrm{min}^{-1}\right)=1.59-0.009$ (duration) $-0.006(\mathrm{Wt}) \mathrm{f}=4.32 P=0.02$.

$P=0.0002$ ). The regression equation for this model is:

$\mathrm{TD}_{95}$ atracurium infusion $=8.36-2.02(\mathrm{MAC})-0.028$ (age) $\mu \mathrm{g} \cdot \mathrm{kg}^{-1} \cdot \mathrm{min}^{-1} \mathrm{f}=30.82 P=0.0002$.

The vecuronium model found duration of infusion (coeff $=0.005 \pm 0.002 P<0.05$ ) and weight of the patient (coeff $0.006 \pm 0.003 P=0.05$ ) to be predictors of the rate of infusion. The regression equation for this model is:

$\mathrm{TD}_{95}$ vecuronium infusion $=1.59-0.005$ (duration)

$$
-0.006(w t) \mu \mathrm{g} \cdot \mathrm{kg}^{-1} \cdot \mathrm{min}^{-1} \mathrm{f}=4.32 P<0.05 \text {. }
$$

The end-tidal halothane and isoflurane levels were con- verted to their respective MAC equivalents using previously published values. ${ }^{23,24}$ We compared the halothane and isoflurane data separately with the multivariate model using the age-adjusted MAC level to normalize the inhalation agent values. The coefficient for isoflurane was -1.96 \pm 0.34 and the corresponding coefficient for halothane was $-2.12 \pm 0.22 P=0.56$. We therefore treated the two groups as the same in our multivariate model. Thus atracurium infusion rates were reduced about two micrograms for each additional MAC added to the anaesthetic.

\section{Reversal of neuromuscular blockade}

Pancuronium blockade was reversed from less twitch depression $(85.6 \%)$ than the other four groups $(95.3 ; 96.5$; 94.0 ; and $95.7 \%$ respectively, ANOVA $P=0.01$ ). Despite lower twitch depression, the pancuronium reversal $\mathrm{T}_{1} / \mathrm{T}_{\mathrm{lc}}(25-75 \%)$ took a mean of $7.06 \pm 0.27 \mathrm{~min}$ which was longer than groups A1: $4.8 \pm 0.21$; $\mathrm{A} 2: 50 \pm 0.17$; A3: $4.3 \pm 0.23$; and $V: 3.7 \pm 0.18 \mathrm{~min}$ respectively (ANOVA $P=0.05$ ). The time for neuromuscular function to return to $T_{4} / T_{1}(0.8)$ after pancuronium block was 23.24 $\pm 28.8 \mathrm{~min}$. The mean reversal times for all other groups were less than half of this (A1: $11.9 \pm 0.84 ; \mathrm{A} 2: 10.46 \pm$ 0.21 ; A3: $12.1 \pm 0.56$; and $V: 12.3 \pm 0.81 \mathrm{~min}$ respectively, ANOVA $P=0.001$ ) (Table IV).

Multivariate analysis using forward stepwise regression modelling considered five factors: age, weight, duration of infusion, inhalational agent and the $T_{1} / T_{1 c}$ at the time of reversal on the reversal time $\left(\mathrm{T}_{4} / \mathrm{T}_{1}=0.8\right)(\mathrm{Table} \mathrm{V})$. The only significant predictor of reversal after atracurium 
TABLE IV Characteristics of reversal: mean $\pm \mathrm{SD}$ (range)

\begin{tabular}{|c|c|c|c|c|}
\hline Study group & $\begin{array}{l}T_{1} T_{l \mathrm{f}} \\
\text { (\% at reversal) }\end{array}$ & $\begin{array}{l}T, T_{l c}(25-75 \%) \\
\min \end{array}$ & $\begin{array}{l}T_{f} T_{l}(5-80 \%) \\
\min \end{array}$ & $\begin{array}{l}T D_{9 s} \text { at reversal } \\
\left(\mu g \cdot \mathrm{kg}^{-1} \cdot \mathrm{min}^{-1}\right)\end{array}$ \\
\hline Al & $\begin{array}{l}4.7 \pm 3.6 \\
(1-10)\end{array}$ & $\begin{array}{l}4.8 \pm 2.1 \\
(2.6-7.1)\end{array}$ & $\begin{array}{l}11.9 \pm 8.4 \\
(4.1-30.5)\end{array}$ & $\begin{array}{l}7.6 \pm 1.1 \\
(6-10)\end{array}$ \\
\hline A2 & $\begin{array}{l}3.5 \pm 1.3 \\
(1-6)\end{array}$ & $\begin{array}{l}5.0 \pm 1.7 \\
(2.1-7.6)\end{array}$ & $\begin{array}{l}10.5 \pm 2.1 \\
(4.1-15.6)\end{array}$ & $\begin{array}{l}4.7 \pm 1.1 \\
(2.9-7.0)\end{array}$ \\
\hline $\mathrm{A} 3$ & $\begin{array}{l}6.0 \pm 3.5 \\
(3-12)\end{array}$ & $\begin{array}{l}4.3 \pm 2.3 \\
(4.2-6.8)\end{array}$ & $\begin{array}{l}12.1 \pm 5.6 \\
(8.3-23.3)\end{array}$ & $\begin{array}{l}6.1 \pm 1.4 \\
(3.9-8.0)\end{array}$ \\
\hline $\mathrm{v}$ & $\begin{array}{l}4.3 \pm 2.0 \\
(1-8)\end{array}$ & $\begin{array}{l}3.7 \pm 1.8 \\
(1-8)\end{array}$ & $\begin{array}{l}12.3 \pm 8.1 \\
(4.9-31)\end{array}$ & $\begin{array}{l}0.94 \pm 0.23 \\
(0.57-1.6)\end{array}$ \\
\hline $\mathrm{P}$ & $\begin{array}{l}14.4 \pm 13.0 \\
(4-45)^{*}\end{array}$ & $\begin{array}{l}7.1 \pm 2.7 \\
(2.8-11.8) \ddagger\end{array}$ & $\begin{array}{l}23.4 \pm 28.8 \\
(4.0-102) \dagger\end{array}$ & \\
\hline
\end{tabular}

$T_{1}=$ the first twitch in a train-of-four; $T_{1 c}=$ the control value for the EMG; $T_{4}=$ the fourth twitch in the train-offour; $* P=0.01 ; \nmid P=0.001$ ( $P$ compared with all other groups); $\ddagger P=0.05$ ( $P$ compared with $\mathrm{V}$ only).

TABLE V Multivariate analysis of predictors of reversal (Usefulness of age, wt, duration of infusion, $T_{1} / T_{1 c}$ (at time of reversal), and the inhalational agent to predict the reversal time. Reversal time is defined as the time in minutes to achieve $T_{4} / T_{1}=0.8$ )

\begin{tabular}{llcl}
\hline & Variable & Coeff $+S D$ & $P$ value \\
\hline Atracurium & Age(yr) & $0.136 \pm 0.049$ & 0.050 \\
& Wt(kg) & $-0.007 \pm 0.061$ & 0.904 \\
& Duration(min) & $0.006 \pm 0.011$ & 0.594 \\
& $t^{\prime} t^{c}(\%)$ & $0.256 \pm 2.06$ & 0.230 \\
& MAC & $-0.111 \pm 0.159$ & 0.421 \\
& & & \\
Vecuronium & Age(yr) & $2.840 \pm 0.051$ & 0.001 \\
& Wt(kg) & $-0.042 \pm 0.060$ & 0.413 \\
& Duration(min) & $0.120 \pm 0.180$ & 0.002 \\
& $t^{1} t^{\mathrm{c}}(\%)$ & $0.441 \pm 0.260$ & 0.238 \\
\hline
\end{tabular}

Regression coefficients are computed using analysis of variance: the regression equations are derived using a forward stepwise model where each variable must add to the predictive value $P=0.05$. The regression equations are: (a) atracurium reversal $(\mathrm{min})=7.87+0.136$ (age) $\mathrm{f}=2.87 P=0.05$; (b) vecuronium reversal $(\mathrm{min})=-7.25+$ 0.284 (age) +0.12 (duration) $f=18.01 P=0.0002$.

infusion was age (coeff $=0.136 \pm 0.05 P=0.05$ ). The regression equation for the model was:

$$
\begin{aligned}
& \text { Atracurium reversal time }(\mathrm{min})=7.87 \pm 0.136(\text { age }) \\
& \mathrm{f}=2.87 ; P=0.05 \text {. }
\end{aligned}
$$

The vecuronium model predicting reversal shows that age (coeff $=2.84 \pm 0.51 P=0.0002$ ) and the duration of infusion (coeff $=0.12 \pm 0.01 P=0.0001$ ) are the only significant variables in the model. The regression equation for the model is:

$$
\begin{array}{r}
\text { Vecuronium reversal time }(\mathrm{min})=-7.25+0.284 \text { (age }) \\
+0.12(\text { duration }) ; \mathrm{f}=18.01 ; P=0.0002 .
\end{array}
$$

This model predicts that vecuronium blockade would be reversed faster than atracurium in procedures lasting less than three hours or in younger patients. However, in cases lasting more than three hours, and in the elderly, atracurium blockade would be reversed faster than vecuronium.

\section{Discussion}

This study has shown that in tightly controlled conditions there is considerable variation in the infusion rate required to maintain $95 \%$ twitch depression $\left(\mathrm{T}_{\mathrm{l}} / \mathrm{T}_{1 \mathrm{c}}=0.05\right)$. We have found that the dose of vecuronium required to maintain $95 \%$ twitch depression varies with the duration of infusion and the weight of the patient. Atracurium infusions were found to vary with age.

The mean doses for both atracurium and vecuronium were similar to doses reported by other investigators. $^{10,12,13,17-22}$ The large variation that we report can be explained on the basis of the differential effect of age and the duration of the infusions. The variation with age of both atracurium ${ }^{26}$ and vecuronium ${ }^{27}$ have been previously reported but it has not been reported previously that the duration of infusion affects the infusion rate for vecuronium. This phenomenon may be explained on the basis of accumulation of an active metabolite. Three desacetylvecuronium has been shown to be such a metabolite ${ }^{28}$ which is cleared more slowly than the parent compound. ${ }^{29}$ A second explanation for the changing infusion rates for vecuronium and not atracurium may be longer elimination half-life or a larger volume of distribution for vecuronium..$^{30,31}$

Isoflurane and halothane have similar effects on atracurium dose requirements. The dose of atracurium is reduced by approximately $2 \mu \mathrm{g} \cdot \mathrm{kg}^{-1} \cdot \mathrm{min}^{-1}$ for every increment of 1 MAC. A similar potentiation has been documented for atracurium infusions when used in paediatric patients ${ }^{32.33}$ and with bolus dosing in adults. ${ }^{34}$ The effect of inhalation agents on vecuronium infusion requirements has been previously reported. ${ }^{13}$

The second stage of this study found that profound 
neuromuscular blockade achieved with infusions of intermediate acting agents, under a variety of anaesthetic conditions, can be reversed nearly two times faster than that maintained by the use of intermittent pancuronium boluses. The mean reversal time of pancuronium was $23.24 \pm 28.8$ mins. With this large variation, one hour after reversal the block will not be adequately reversed in $10 \%$ of patients. We eliminated other factors which might have potentiated pancuronium blockade. There were no antibiotics or inhalation agents used to delay the reversal further. The reversal times for pancuronium in common clinical situations may be longer. Our measure of reversal time is more strict than others, but the use of less strict criteria may be associated with a decreased ability to protect the airway even though patients can maintain normocapnia. None of the 75 patients in this study had any clinical signs of residual paralysis.

Atracurium and vecuronium block is reversed in a similar time. After steady state $95 \%$ twitch depression the mean reversal time is approximately $12 \mathrm{~min}$. The multivariate regression models predicting reversal time for atracurium and vecuronium are different. Atracurium reversal is predicted on the basis of age. Using the regression equation derived from this study, a 25 -yr-old subject would require $11.2 \mathrm{~min}$ to reverse an atracurium blockade; an 80 -yr-old would require $18.6 \mathrm{~min}$. The vecuronium model uses age and the duration of the infusion to predict recovery time. The mythical 25 -yr-old after a two-hour infusion would require $13 \mathrm{~min}$ to recover from vecuronium blockade; if the infusion time were increased to four hours the 25 -yr-old requires $28 \mathrm{~min}$ to recover from the neuromuscular block. If we now consider the 80-yr-old with a two-hour infusion the model predicts a reversal time of $29 \mathrm{~min}$.

A recent study indicated $d^{35}$ that, after long and short infusions of these drugs, the spontaneous recovery of either was not significantly different. However, several differences in the study design are apparent; first the level of block was less (twitch depression was $90 \%$ ); second, all patients were allowed to recover to some extent before reversal, and neuromuscular blockade was antagonised with edrophonium. Finally, the age of the subjects was not reported. The study we report was not designed to test kinetics or dynamics. The prediction models of reversal time are consistent with both the accumulation of an active metabolite or decreased organ clearance of the drug. Further, the accumulation of an active metabolite could explain the time-related decrease of infusion rates with time. Previous studies have indicated there may be potential difficulty reversing vecuronium in the elderly. ${ }^{10}$

The finding of prolonged recovery with prolonged infusions and in the elderly has clinical importance since these patients are often those who manifest postoperative complications. ${ }^{36}$

\section{Conclusion}

Infusions of atracurium and vecuronium can offer a stable degree of twitch depression for long surgical procedures. Atracurium reached a constant infusion rate quickly, whereas some patients having vecuronium infusions never maintained steady states for more than $15 \mathrm{~min}$. Inhalation agents reduced the infusion requirements in a dose-dependent manner, but the addition of a potent inhalational agent did not affect the recovery times when compared to a nitrous/narcotic technique. The steady state infusions of atracurium and vecuronium were reversed in about half the time of intermittentently administered pancuronium. A multivariate model predicting reversal of the former agents after infusion shows age to be important for both atracurium and vecuronium. The duration of vecuronium infusion also predicts reversal time.

Using the continuous infusion technique, twitch depression can be maintained, and then safely reversed in less than $20 \mathrm{~min}$ for most patients.

\section{References}

1 Beecher HI, Todd DP. A study of deaths associated with anesthesia and surgery based on a study of 599,548 anaesthetics in 10 institutions, 1948-1953 inclusive. Ann Surg 1954; 50: 2-34.

2 Lunn JN, Mushin WW. Mortality associated with anaesthesia. Anaesthesia 1982; 37: 856-9.

3 Viby-Mogensen J, Jensen NH, Engbaek J. Tactile and visual evaluation of the response to train-of-four nerve stimulation.Anesthesiology 1985; 63: 440-3.

4 Pavlin EG, Holle RH, Schoene RB. Recovery of airway protection compared with ventilation in humans after paralysis with curare. Anesthesiology 1989; 70: 381-5.3.

5 Sharpe MD, Lam AM, Nicholas JF, et al. Correlation between integrated evoked EMG and respiratory function following atracurium administration in unanaesthetized humans. Can J Anaesth 1990; 37: 307-12.

6 Viby-Mogensen J, Jorgensen BC, Ording $H$. Residual curarization in the recovery room. Anesthesiology 1979; 50: $539-41$.

7 Bremer GH, Rosental P. Post operative neuromuscular function. Anesth Intensive Care 1986; 14: 41-5.

8 Bevan DR, Smith CE, Donati F. Postoperative neuromuscular blockade: A comparison between atracurium, vecuronium, and pancuronium. Anesthesiology 1988; 69: 272-6.

9 Brull SJ, Silverman DG, Ehrenwerth J. Problems of recovery and residual neuromuscular blockade: pancuronium vs. vecuronium. Anesthesiology 1988; 69: A473. 
10 Kopman AF. Recovery times following edrophonium and neostigmine reversal of pancuronium, atracurium, and vecuronium steady-state infusions. Anesthesiology 1986; 65: $572-8$.

11 Delisle $S$, Bevan DR. Impaired neostigmine antagonism of pancuronium during enflurane anaesthesia in man. $\mathrm{Br} \mathrm{J}$ Anaesthesia 1982; 54: 441-5.

12 Dernovoi B, Agoston S, Barvais L, Baurain M, Lefebvre R, $D$ 'Hollander $A$. Neostigmism antagonism of vecuronium paralysis during fentanyl, halothane, and enflurane anaesthesia. Anesthesiology 1987; 66: 698-701.

13 Swen J, Gencarelli PJ, Koot HWJ. Vecuronium infusion dose requirements during fentanyl and halothane anesthesia in humans. Anesth Analg 1985; 64: 411-4.

14 Cannon JE, Fahey MR, Castagnoli KP, et al. Continuous infusion of vecuronium: the effect of anaesthetic agent. Anesthesiology 1987; 67: 503-6.

15 Ali HH, Savarese JJ, Lebowitz PW, Ramsey FM. Twitch, tetanus, and train of four as indices of recovery from nondepolarizing neuromuscular blockade. Anesthesiology 1981; 54: 570-3.

16 Kopman AF. The relationship of evoked electromyographic and mechanical responses following atracurium in humans. Anesthesiology 1985; 63: 208-11.

17 Noeldge G, Hinsken H, Buzello W. Comparison between the continuous infusion of vecuronium and the intermittent administration of pancuronium and vecuronium. $\mathrm{Br} \mathrm{J}$ Anaesth 1984; 56: 473-7.

18 Gramstad $L$, Lilleaasen $P$. Neuromuscular blocking effects of atracurium, vecuronium and pancuronium during bolus and infusion administration. $\mathrm{Br} \mathrm{J}$ Anaesth 1985 ; 57: 1052-9.

19 Eager BM, Flynn P, Hughes R. Infusion of Atracurium for Long Surgical Procedures. Br J Anaesthesia 1984; 56; 447-51.

20 D'Hollander A, Czeruki $R$, DeVille A, Cuvelier F. Stable muscle relaxation during abdominal surgery using combined intravenous bolus and demand infusion: clinical appraisal of Org NC45. Can Anaesth Soc J 1982; 29 : $136-41$.

21 Fierro $G$, Trobbaini $G$, Sanfilippo $M$, Vilardi $V$, Favaro $V$, Menichetti $A$. Continuous infusion of vecuronium. Acta Anaesthetica Italica 1989; S1: 43-50.

22 Rowlands $D E$. Simple atracurium infusions. $\mathrm{Br} J$ Anaesth 1985; 51: 542.

23 Gregory GA, Eger EI, Munson LS. The relationship between age and halothane requirement in man. Anesthesiology 1969; 30: 488-91.

24 Stevens WC, Dolan WM, Gibbons RT, et al. Minimum alveolar concentrations (MAC) of isoflurane with and without nitrous oxide in patients of various ages. Anesthesiology 1975; 42: 197-200.
25 Donati $F$, Smith CE, Bevan DR. Dose-response relationships for edrophonium and neostigmine as antagonists of atracurium and vecuronium neuromuscular blockade. Anesthesiology 1989; 71: 37-43.

26 Beattie WS, Buckley DN, Deguzman C, Hewson JR, Forrest JB. The effect of age on the duration of block produced by bolus atracurium. Can J Anaesth 1988; 35: S118-9.

27 D'Hollander A, Massaux F, Nevelsteen M, Agoston S. Age-dependent dose-response relationship of ORG NC45 in anaesthetized patients. Br J Anaesth 1982; 54: 653-7.

28 Marshall IG, Gibb AJ, Durant NN. Neuromuscular and vagal blocking actions of pancuronium bromide, its metabolites, and vecuronium bromide (ORG NC 45) and its potential metabolites in the anaesthetized cat. $\mathrm{Br} \mathrm{J}$ Anaesth 1983; 55: 703-14.

29 Segredo V, Matthay MA, Sharma ML, Gruenke LD, Caldwell JE, Miller RD. Prolonged neuromuscular blockade after long-term administration of vecuronium in two critically ill patients. Anesthesiology 1990; 72: 566-70.

30 Cronnelly $R$, Fisher D, Miller RD, Gencarelli P, NgugenGruenka $L$, Catagnoli N. Pharmacokinetic and pharmacodynamics of vecuronium (ORG nc 45) and pancuronium in anesthetized humans. Anaesthesiology 1983; 58: 405-8.

31 Ward $S$, Wright $D$. Combined pharmacodynamic and pharmacokinetic study of single bolus atracurium. $\mathrm{Br} \mathrm{J}$ Anaesth 1983; 55: 35S-38S.

32 Brandom BW, Cook DR, Woelfel SK, Rudd GD, Fehr B, Lineberry $C G$. Atracurium infusion requirements in children during halothane, isoflurane, and narcotic anesthesia. Anesth Analg 1985; 64: 471-6.

33 Goudsouzian E, Martyn J, Rudd GD, Liu LMP, Lineberry $C G$. Continuous infusion of atracurium in children. Anaesthesiology 1986; 64: 171-4.

34 Rupp S, Fahey A, Miller RD. Neuromuscular effects of atracurium during halothane nitrous oxide and enflurane nitrous oxide anesthesia in humans. Anesthesiology, 1985; 63: 16-9.

35 Ratcliff A, LawMin JC, Donati F, Bevan DR. Neuromuscular recovery following short and long infusions of atracurium and vecuronium. Can J Anaesth 1990; 38: A 128.

36 Forrest JB, Cahalan MK, Rehder $K$, et al. Multicenter Study of General Anaesthesia. II, Results. Anesthesiology 1990; 72: 262-8. 